3-17-2017

\title{
An Analogy Explanation for the Evaluation of Entrepreneurial Opportunities
}

Ugur Uygur

Loyola University Chicago, uuygur@luc.edu

Follow this and additional works at: https://ecommons.luc.edu/business_facpubs

Part of the Entrepreneurial and Small Business Operations Commons

Author Manuscript

This is a pre-publication author manuscript of the final, published article.

\section{Recommended Citation}

Uygur, Ugur. "An Analogy Explanation for the Evaluation of Entrepreneurial Opportunities," Journal of Small Business Management, forthcoming

This Article is brought to you for free and open access by the Faculty Publications and Other Works by Department at Loyola eCommons. It has been accepted for inclusion in School of Business: Faculty Publications and Other Works by an authorized administrator of Loyola eCommons. For more information, please contact ecommons@luc.edu.

\section{(c) $($ () $\ominus$}

This work is licensed under a Creative Commons Attribution-Noncommercial-No Derivative Works 3.0 License. (c) 2017 International Council for Small Business. 


\title{
An Analogy Explanation for the Evaluation of Entrepreneurial Opportunities
}

\author{
Ugur Uygur \\ Assistant Professor of Entrepreneurship \\ Quinlan School of Business, Loyola University Chicago \\ 820 N. Michigan Ave., Chicago, IL 60611, USA \\ phone: 1-312-915-6077; email: uuygur@luc.edu
}

* Accepted for publication at Journal of Small Business Management

\begin{abstract}
Entrepreneurs evaluate opportunities under conditions of uncertainty; they make judgments. In order to understand these evaluations, I develop an analogical model that represents an entrepreneurial opportunity in the mind of an individual. The model proposes that an opportunity is an analogical knowledge transfer from a source business domain to a target business domain. According to the model, the cognitive distance between the domains influences the opportunity evaluation. Additionally, the inspiration behind the analogy construction influences the opportunity evaluation. The empirical design employs a hypothetical scenario experiment and the results show that the two analogical properties matter for evaluation.
\end{abstract}

Keywords: entrepreneurial cognition; analogy; opportunity evaluation; opportunity representation; scenario experiment; knowledge structure 


\section{Introduction}

"[W]e need to know how the business world is represented in the cognitions of people who do, and people who do not, found new ventures.” (Shaver and Scott, 1991)

How representations of the business world form in an individual's mind is a central cognitive puzzle for entrepreneurship research (Grégoire et al., 2011). Before an entrepreneur founds a firm, an opportunity is only an idea in his or her mind. The opportunity, which is the novel business idea, is represented using the individual's existing knowledge structures (Baron, 2006). A positive subjective evaluation of the idea reflects the construction of the belief that prospective customers will pay more than the associated costs for a novel product or service (Shane and Venkataraman, 2000) and sets off a chain of events that form the basic building blocks in the economy (Busenitz et al., 2003; Mahoney and Michael, 2005). Constructing such an opportunity evaluation requires a difficult judgment call (McMullen and Shepherd, 2006), however. A cognitive answer to the difficulties of opportunity evaluation relies, partly, on the way the opportunity is represented in the mind of the person making that judgment. This study thus examines that larger question: How does the representation of a novel business idea in the mind of an individual influence the evaluation of the idea?

Several well-known venture histories illustrate the complexity of opportunity evaluation. For example, when its founder started Netflix, almost all the routines of the envisioned firm had been in practice in different industries for a long time. Many did not believe in the profit potential of the idea, however. Similarly, the founder of Amazon.com faced a difficult time at the beginning; others could not comprehend the idea of combining mail-order businesses with the internet. The opportunity evaluation problem is not only about missed opportunities (Hogarth and Karelaia, 2012), it can also be about overconfidence (Simon and Shrader, 2012). For instance, in the case of Webvan, an online grocery business, the entrepreneurial idea received strong support from virtually all the stakeholders involved. The idea of transferring the Amazon.com model to groceries made sense to both entrepreneurs and investors. With the advantage of hindsight, we can fashion explanations for the differences in observed 
performance. The critical evaluation of the opportunity occurs before the firm is organized and the outcomes are observed, however. Thus we need to understand how the individual constructs the opportunity in her mind at the time of entrepreneurial judgment (Dimov, 2007b).

Since Shaver and Scott pointed out the representation puzzle a couple of decades ago, entrepreneurship research has made only scattered advances toward understanding how an opportunity is represented in the mind (e.g. Sarasvathy, 2001). The literature addresses this fundamental question by focusing mostly on individual traits and capabilities rather than the opportunity idea (Dahlqvist and Wiklund, 2012). A few recent investigations, however, examine the knowledge structures that prospective entrepreneurs employ as they imagine the opportunities they evaluate (Grégoire et al., 2011). Mitchell et al. (2002), for example, propose that entrepreneurs use scripts as they recognize, evaluate, and exploit opportunities. Relying on a different knowledge structure, the prototype, Baron and Ensley (2006) maintain that prospective entrepreneurs use pattern recognition when they compare events around them with what they believe an opportunity ought to be. In a recent study, Grégoire and Shepherd (2012) model opportunities as technology-market combinations. These studies pioneered the use of knowledge structures as models of opportunity representation in the individual's mind.

The complexity of the entrepreneurial judgment task allows individuals to use all of these knowledge structures simultaneously, and our understanding of the entrepreneurial mind at the time of opportunity evaluation is yet incomplete. Existing models rely on either special knowledge structures that are too specific to the entrepreneurial task or ambiguous concepts that are difficult to reconcile with other knowledge-based theories of business phenomena (c.f. Grant, 1996; Kogut and Zander, 1992; Nelson and Winter, 1982). Entrepreneurial events are infrequent; therefore, a cognitive explanation of entrepreneurial judgment will be grounded only if it employs a generic cognitive mechanism that is possessed not only by some special individuals (c.f. Sarasvathy and Dew, 2005). In addition, entrepreneurs rely heavily on prior business knowledge as they think about novel opportunities (Shane, 2000; Ward, 2004); therefore, the cognitive mechanism of choice also needs to demonstrate how a new idea can be represented using existing business knowledge in a person's mind. A structured review of the entrepreneurial cognition 
research reaches a similar conclusion: We need to identify the cognitive elements relevant to entrepreneurship and the cognitive mechanisms that operate on them (Grégoire et al., 2011).

Building on and extending the entrepreneurial cognition literature, I advance a model of opportunity representation using a generic cognitive mechanism (i.e., analogy) and an established theory of knowledge representation in a firm (i.e., routines). The resulting analogical model contributes to the entrepreneurship literature a novel theory of envisioning opportunities while offering an intuitive explanation of how business knowledge can be re-used to imagine a new firm organization. "Nothing comes from nothing” is a common theme in many philosophical systems. Cognitive science research shows that we use knowledge structures to represent existing knowledge and operate cognitive mechanisms on them to learn and to create new ideas (Holyoak and Thagard, 1995). The theoretical model advanced in this study contributes to the investigation of analogical mechanisms in entrepreneurship research, which is in its very early stages (e.g. Cornelissen and Clarke, 2010; Grégoire and Shepherd, 2012; Ward, 2004). In addition, the empirical study contributes an experimental design that exploits the inference power of a controlled study in the context of a complex business phenomenon (cf. Billinger et al., 2014; Loch et al., 2013).

\section{Theoretical background}

The theoretical model developed in this study articulates an analogical representation of an entrepreneurial opportunity in the mind of the individual. The variation of interest is the evaluation of opportunity; hence, the immediate interpretation of the findings contributes to the opportunity evaluation literature (c.f. Haynie et al., 2009; McMullen and Shepherd, 2006). In doing so, the model builds on the convergence of two established theories in neighboring fields to entrepreneurial cognition: analogy from cognitive sciences (e.g. Gentner et al., 2001; Hofstadter, 2001; Holyoak and Thagard, 1995) and routines from the knowledge-based theory of the firm (e.g. Kogut and Zander, 1992; Nelson and Winter, 1982). 


\section{Subjectivity of opportunity evaluation}

Individuals' evaluations of the profit potential of an idea, which depends on the future satisfaction of customers' needs, are subjective and heterogeneous (Eckhardt and Shane, 2003; Knight, 1921; Mahoney and Michael, 2005; McMullen and Shepherd, 2006). Existing literature on entrepreneurial opportunities, however, does not provide us with many tools to explain that variation. Most promising personality traits, such as attitude towards risk, locus of control, and need for achievement, hardly explain entrepreneurial behavior (Eckhardt and Shane, 2003; Krueger Jr and Reilly, 2000; Shook et al., 2003). Influential Austrian economics perspectives, which emphasize the subjectivity of opportunity evaluation, do not provide a clear answer either. Schumpeter (1934) characterizes the entrepreneur as a daring and innovative person, but his work does not include a distinctive decision-making framework (Kesting, 2007). Kirzner (1997) points to alertness as a key cognitive characteristic, but empirical support for his view is lacking (Busenitz, 1996). After surveying the literature, Dimov (2004) concludes that the subjectivity of the entrepreneurial process requires understanding the opportunity from the entrepreneur's perspective, but that “no existing definition of opportunity captures an entrepreneur's view of it” (p. 148).

Following that critique, entrepreneurial cognition research has progressed toward understanding how an opportunity may exist in the prospective entrepreneur's mind. A few recent studies show how individuals could structure their prior knowledge as they construct opportunities in their minds. First, Mitchell and colleagues (2000) employ cognitive scripts as the knowledge structure of choice. Scripts are knowledge structures in an individual's mind that are related to frequently experienced occasions. The classic example is the restaurant script: Individuals know how to interact in restaurants with the staff in order to be served. Mitchell et al. (2000) identify the scripts possessed by entrepreneurs and differentiate them from other individuals. As an alternative, Baron and Ensley (2006) employ prototypes as the knowledge structure of choice. Prototypes are cognitive constructs that represent ideal forms. For example, a person might have a prototype for an apple, which is a knowledge structure in her mind. Whenever she has a potential apple object in her sight, she compares the object to the prototype. If it is a match, she decides that the object is an apple. Applying this concept, Baron and Ensley (2006) suggest 
that entrepreneurs also have a prototype for "business opportunity." More recently Grégoire and Shepherd (2012) present the results of a study that employed structural alignment as a cognitive mechanism of organizing prior knowledge structures in the mind. In their theoretical development, the researchers model an opportunity as a techonology-market combination. They then explain how opportunities differ in terms of the match between the attributes of a technology and the attributes of a market. Their results show that entrepreneurs are sensitive to that heterogeneity in opportunities. These research studies provide excellent justification and impetus for the entrepreneurial cognition field.

Opportunity representation is a complicated cognitive puzzle, and several other cognitive processes are expected to be simultaneously involved in addition to scripts, prototypes, and structural alignment. To make the case for an alternative cognitive mechanism, the next sub-section builds the case for the distinctive element in an entrepreneurial opportunity--novelty--and how that novelty is identified.

\section{Defining a Novel Opportunity in the Context of Routines}

An entrepreneurial opportunity differs from the larger set of all profit opportunities because of its newness (Shane and Venkataraman, 2000). An opportunity is novel in an entrepreneurial sense if it requires a new framework for making decisions (Langlois, 1982). If, in contrast, an opportunity’s potential can be evaluated using existing frameworks, then it requires a form of decision making like that of a producer as an economic agent in a neoclassical sense (Adaman and Devine, 2002; Foss and Klein, 2012).

To understand what makes an entrepreneurial opportunity novel, we need to be able to compare the new with the old (Rosenkopf and McGrath, 2011), which can be a difficult task (Csikszentmihalyi, 1996). First, we need to understand the existing knowledge from which the novel idea is deviating (Michael, 2007). Strategy research provides tools to help explain existing knowledge in firms. Evolutionary economics and knowledge-based theories recognize that a firm is composed of employees’ repeated activities (Grant, 1996; Kesting, 2007; Loch et al., 2013), and thus it becomes a repository of collective knowledge or a collection of sequenced activities (Kogut and Zander, 1992). These firm-level capabilities are analogous to the skills of an individual. Nelson and Winter (1982) define them as routines. By 
suggesting the founding of a new firm, an entrepreneurial opportunity implies one or more routines that do not yet exist in practice; rather, at this stage, they exist only in an individual's mind. In this sense, they are novel routines. An entrepreneurial opportunity therefore incorporates a knowledge proposition (Harper, 1996) that consists of a set of routines applied in a novel setting (Kaul, 2013).

Although researchers have traditionally considered routines as firm-level constructs, they also relate to other levels of analysis. At the macro level, for example, routines play an important role in economic change. As blocks of knowledge, routines represent the "genes" that carry over from one organization to others (Kogut and Zander, 1992). At the micro level, routines have cognitive counterparts: scripts (see Journal of Management Studies, December 2012 Special Issue for a thorough examination). Cognitive science research has demonstrated that an individual stores scripts as chunks in his or her mind (Abelson and Black, 1986; Sharkey, 1986). In fact, Nelson and Winter (1982) suggest that the terms “script," “routine,” and "program” have been used to represent the same concept. When evaluating an entrepreneurial opportunity, the individual imagines a firm organization accomplishing a set of routines that will materialize if he or she decides to found the firm. The routine construct is useful for opportunity representation in this cognitive sense of a script. Entrepreneurial cognition research has shown that entrepreneurs use scripts in many stages of new venture development (Mitchell et al., 2002). As the entrepreneur contemplates on an opportunity, she consults script-like knowledge structures that represent the routines of the future venture she will start.

Thus, the following conceptual aspects emerge. An entrepreneurial opportunity: (1) consists of one or more routines (that is, knowledge structures that show how to perform the steps necessary to accomplish a business goal); (2) proposes that a routine will be applied in a novel setting (such that it becomes a novel routine); and (3) contains the expectation that profits will emerge because it will satisfy a customer need. 


\section{Representation of the novel opportunity as analogy: Model and Hypotheses}

According to cognitive theories of analogy, creation of the new is only possible through the old. On a superficial level, novelty is a change of a convention, an existing practice. More precisely, an entrepreneurial opportunity is the consequence of a novelty generation mechanism in the mind of an individual. Gentner (1983: 156) defines analogy as “an assertion that a relational structure that normally applies in one domain can be applied in another domain.” As Hofstadter (2001) eloquently conveyed it, an analogy is "the very blue that fills the whole sky of cognition" (p. 499). Through analogy, an individual adapts a piece of knowledge that works in one domain to a new domain (Holyoak and Thagard, 1995).

Cognitive science researchers have identified analogical thinking as a fundamental process through which individuals create and learn new knowledge (Gentner, Holyoak and Kokinov, 2001). Studies demonstrate the mind's use of analogy in processes ranging from child learning to scientific discovery (Holyoak and Thagard, 1995). Ward (2004) raised the idea that entrepreneurial opportunities may also be the consequence of an analogical mechanism, but a structured modeling of an opportunity as an analogy has not yet been completely developed (see Cornelissen and Clarke, 2010; Grégoire et al., 2010a for pioneering studies with related agendas).

Hence, the central argument in this paper is the following: An opportunity may be represented as an analogical proposition in the mind of the individual. The prospective entrepreneur proposes that he or she can apply a routine that normally satisfies a need in one domain to another domain. This, in turn, is expected to satisfy another need and bring forth profits. More formally, we can describe an existing business as: Routine-X satisfies Need-A (see Figure 1). Let Domain-1 denote the business that will function as the source domain. Let Domain-2 denote a business in which Routine-Y satisfies Need-B. That will be the target domain.

One way to construct the analogy is to observe that Need-A is similar to Need-B. If Domain-1 is analogous to Domain-2, then the "satisfies" relationship should hold in both. Therefore, the individual 
concludes that Need-B will be satisfied by Routine-X (the upward arrow in Figure 1). The transfer of the routine from one domain to another produces an entrepreneurial opportunity.

Insert Figure 1 about here

The knowledge components in the analogy construction above require further elaboration. At least two domains are necessary to construct an analogy. In the entrepreneurial analogy construction, each domain consists of a customer need and a routine to satisfy it. It is important to separate the customer need from the way it is satisfied (Michael, 2007), and therefore, I define need as a condition requiring relief. For the purposes of the theoretical development here, I consider needs exogenous and beyond the influence of the entrepreneur.

In contrast, a routine specifies how a need is satisfied. The actual routine employed by an existing firm is not a cognitive object of interest, however, nor is the actual need of a particular customer group. Instead, the mind of the individual is the level of analysis, and our concern is about how an entrepreneurial opportunity is represented in an individual's mind. The schemas containing the routines and the needs in the entrepreneur's mind form the building blocks of the analogy that give rise to an entrepreneurial opportunity. Therefore, I define a routine as a knowledge structure in an individual's mind, such that a sequence of actions will produce a particular outcome. This definition of the routine relies on a knowledge structure equivalent to scripts (Mitchell et al., 2002; Smith et al., 2009b); however differs from them by its knowledge. Previous script research in entrepreneurial cognition have examined knowledge of how to create a new company. By routines in this context, I focus on the domain knowledge of how a particular business works. We can conceive of a routine as the first component of a means-ends framework, such that the participants accomplish a goal within a business transaction through the execution of some actions in a certain sequence.

There are two possible paths for the analogy. In the first path, the individual focuses on the existing need in the source domain and discovers another domain that involves a similar customer need. She observes that Need-A is similar enough to Need-B. Even though the existing routines might seem very 
different from each other, she makes the judgment that she can transfer one routine to the other domain. Let us call such analogies Need-inspired opportunities. The upward arrow in Figure 1 above represents this type of analogy construction.

In the second path, the individual discovers the second domain based on the similarity between the two routines. In contrast to the first case, she starts with the observation that the two routines are similar enough. Even though the needs satisfied by these two routines seem very different, she makes the judgment that the existing routine will satisfy the second need. Let us call such analogies Routineinspired opportunities. The downward arrow in Figure 2 represents this type of analogy construction. The crucial judgment about the similarity of the domains is either Need-inspired or Routine-inspired. These are the two types of analogy constructions available to the individual. They generate the same opportunity (Routine-X will satisfy Need-B) in the end but via different paths.

\section{Insert Figure 2 about here}

According to cognitive theories of analogy, three factors affect an analogy’s success: superficial similarities between the two domains, mappings of structural relationships, and the purpose of the analogy (Thagard, 1992). Gentner $(1983,1989)$ emphasizes structural mapping as the most important factor. Grégoire et al. (2010) apply Gentner’s theory in the context of opportunity recognition by executive entrepreneurs and show that structural properties indeed make a difference. In contrast, Holyoak and Thagard (1995) emphasize the third factor, purpose. The purpose of the analogy builds on the fact that the individual is looking for a solution to a problem when she constructs the analogy. Analogies that fit well with the purpose will be more powerful than those that do not. I apply Holyoak and Thagard's theory to explain and predict which types of analogies will be favored in the case of entrepreneurial judgment. When the analogy is successful, it might also register as a match with the entrepreneur’s opportunity prototype (Baron, 2006).

While making an entrepreneurial judgment, an individual constructs and considers the belief that others will pay for a novel product or service. This purpose relies heavily on the premise that others have 
a need that the new routine will satisfy. I anticipate that the emphasis on the business purpose will be a cause of variation in individuals' evaluations of different types of opportunities. In the case of Needinspired opportunities, the prospective entrepreneur has a significant advantage in predicting a business's viability. She has access to the knowledge that some potential customers exist with a proven need, which a novel routine can better satisfy. Even when the underlying structural properties are different, a surfacelevel similarity of the needs will lead to an easier analogical transfer (Gary et al., 2012). Having that knowledge will decrease uncertainty about the opportunity’s profit potential since perceived uncertainty of the demand will be lower. Thus, individuals will perceive the analogy as more successful, because it better satisfies the purpose constraint.

In contrast, in the case of Routine-inspired opportunities, the individual has access only to the knowledge that two routines are similar. She then extrapolates through analogy that the needs would be similar as well. Even though a given technology, or a routine, can be transferred to a wide variety of domains, the choice sets that entrepreneurs actually consider are relatively small (Gruber et al., 2013). The cognitive leap in the Routine-inspired case is a more uncertain one since the purpose of the analogy heavily relies on others with an established need. Therefore, in the case of Routine-inspired opportunities, the uncertainty associated with the customer need will be the cause of a more negative evaluation and less likely to register as a match with the entrepreneur's opportunity prototype (Baron and Ensley, 2006). This yields the following hypothesis:

Hypothesis 1. Individuals will evaluate need-inspired opportunities more positively than routineinspired opportunities.

An entrepreneurial opportunity encompasses two domains: a source domain and a target domain. The conceptual distance between these two domains is the second dimension on which opportunities vary (see Figure 3). Some opportunities represent a significant departure from the source domain while others are closer (cf. Ward, 2004). For illustration, let us consider the flat-fee payment routine of a movie rental business (such as Netflix) as the source analog. An individual creates one entrepreneurial opportunity when he or she transfers this routine to another domain, such as books. An individual creates a different 
entrepreneurial opportunity when he or she transfers that routine to the designer bags domain. These two opportunities are both Routine-inspired opportunities in the sense that the individual identifies the source routine first and subsequently discovers a customer need. However, they differ in the cognitive distance dimension. We may reasonably conjecture that the cognitive distance between the books domain and the movie rental domain is smaller than the distance between the designer bags domain and the movie rental domain. That difference corresponds to the difference in the length of the arrows in Figure 3. For that reason, the latter opportunity represents a larger cognitive leap from the source analog and therefore incurs larger uncertainty. Thus, I define the domain similarity construct as the cognitive distance between the two domains of the analogy underpinning the entrepreneurial opportunity.

Insert Figure 3 about here

According to analogy theory, an increase in cognitive distance causes doubt in the analogy’s success (Holyoak and Thagard, 1995). The face validity of analogical mapping is weaker when the domains are significantly different from each other. Even the similarity of simple characteristics of the domains plays an important role in the evaluation of analogies (Grégoire and Shepherd, 2012; Holyoak and Thagard, 1995). In human cognition, analogy works as a cognitive mechanism because we believe in the performance of the source analog. After establishing the correspondence between the source and target analogs, we conjecture that the routine will also work in the target domain (Gentner, 1983). If the transfer implies a significant leap between the domains, however, then the analogy’s success becomes doubtful. We expect the skills associated with one domain to lose their value if they are transferred to other domains (Negro and Leung, 2012).

This general cognitive reasoning relates particularly well to entrepreneurial judgment. The more distant the domain to which an individual transfers a routine, the less useful existing data become for the individual. The entrepreneur has more difficulty imagining the necessary actions for effective firm operation (Knight, 1921) and the potential outcomes in a distant domain (Langlois, 1982). The existing routines of the source domain do not readily apply in the context of the target domain. In these 
circumstances, the entrepreneur would recognize that the source routines would have to adapt in order to produce the desired outcomes in the target domain. That adaptation would influence the evaluation of the opportunity as it might fail to provide a viable pattern that looks like a complete opportunity prototype in the target domain. When the domains are distant, the different circumstances might disturb the match between the routine and the need, which might result in weaker pattern matching between the evaluated opportunity and the prototype in the mind of the individual (Baron and Ensley, 2006). As a result, the individual is likely to experience more doubt about the success of the analogy and hinder the decision to pursue the venture. Thus, the individual will evaluate the distant opportunity more negatively. In contrast, in the case of a similar domain, the individual will perceive the existing data to be more useful as the source routine can be transferred to the target domain without significant transformation. This yields the following hypothesis:

Hypothesis 2. Domain similarity will relate positively to evaluation of an opportunity.

\section{Method}

In testing the validity of the analogical representation of opportunities, the major methodological challenge stems from bridging two distinct scientific disciplines in a single empirical study. Most empirical studies in cognitive sciences employ simple tasks, such as completing an analogy missing a word. In contrast, entrepreneurship and management disciplines are interested in highly abstract and complex phenomena (Hill and Birkinshaw, 2010). The gap between the methods employed by the hard sciences and the phenomenon of interest in management research brings forth the issue of experimental realism (Patel and Fiet, 2010). Below I explain how the cognition experiment was designed to match the complex research question in entrepreneurship (Acs et al., 2010) and how various threats to causal inference were addressed. The solutions offered in this section may serve as a template for researchers who design experimental studies in entrepreneurship (see also Loch et al., 2013 for a similar study).

Prominent reviews of the literature recommend experimental studies for entrepreneurial cognition research (Baron and Ward, 2004; Grégoire et al., 2011; Mitchell et al., 2004; Mitchell et al., 2007). By 
providing real-time data, experiments help overcome problems related to self-reporting, retrospective reporting, and survival biases (Choi and Shepherd, 2004). In contrast, the unmeasured variables problem is unavoidable in survey methods due to the complexity of the subject. The only way to capture uncertainty about the future is to study the decisions “live,” as they occur (Dimov, 2004). Individuals should think, not recall, for accurate results. Therefore, I used a hypothetical scenario experiment to test the conceptual model proposed in this study (e.g. Haynie et al., 2009; Loch et al., 2013; Sarasvathy et al., 1998).

I conducted the experiment over the course of two semesters in a computer laboratory that holds about 20 participants at a time using a web-based delivery system. Benefits of this delivery system include improved accessibility, complete random ordering of the stimuli, and better measurement of the dependent variable (Schade and Burmeister, 2009). First stage of the experiments was a pre-test with 315 participants to validate the instruments as explained in detail below and the second stage was the main study with 359 participants to test the hypotheses. Both samples consisted of undergraduate students in business administration at a major university in the Midwestern United States. Using students as participants is a common practice in previous studies of a similar nature (e.g. Billinger et al., 2014; Loch et al., 2013). Participation was voluntary, and the students received extra credit for a course in return for their participation in, but not completion of, the study. The guidelines required that students would receive credit irrespective of their performance in the task.

In the experiment, I presented each participant with three scenarios, each of which included a hypothetical entrepreneurial opportunity (see Appendix A). Scholars sometimes treat laboratory studies, especially those that use students, with apprehension in terms of external validity. Previous research, however, shows that a blanket statement about the external validity of laboratory studies is not grounded. The theoretical model does not assume entrepreneurial experience; instead, it focuses on how individuals make judgments before they start ventures similar to the students who made the judgments that led to Microsoft, Facebook, Google, and FedEx. 


\section{The strength of experiments in causal inference}

Ideally, a full factorial within-subject design would be employed to test the hypotheses. Each participant would receive all of the treatments, which should be valid and reliable reflectors of the empirical constructs (Dyer et al., 2008). A repeated measures ANOVA test would be sufficient to measure the fixed effects. However, since no previous study modeled an opportunity as an analogy I had to create the scenario instruments, on which subsequent studies could build. Therefore, significant threats to construct validity, especially in the form of instrument validity and reliability, arose (Patel and Fiet, 2010). In a perfect experiment, all alternative explanations other than the independent variables should be eliminated so that internal validity is achieved. The causal inference is the most important advantage of an experimental methodology (Cook et al., 1979); therefore, in the following section, I describe these threats to validity (see Table 1), as well as the design refinements made to address them.

Insert Table 1 about here

As instruments for each condition, researchers can use two types of scenarios: attribute-driven profiles or actual case-derived scenarios (Shepherd and Zacharakis, 1999). I use the latter kind because they are specific, whereas general attributes of domain and routine similarity would not make sense to a participant without proper training in the theory. Training of the participants would bias them in favor of the hypotheses, however. In contrast, vignette-like short scenarios are specific to a situation and are easier to answer truthfully (Loch et al., 2013; Robertson and Anderson, 1993).

\section{Scenario development and pretest experiment}

According to the theoretical model, individuals can construct the analogy in two alternative ways: routine-inspired and need-inspired. In the need-inspired version of an opportunity, the individual first identifies a problem and then makes a connection to an existing business that could provide a solution. In the routine-inspired version of the same opportunity, the individual first identifies an existing business that she appreciates and then makes a connection to a problem she has. Except for the order of events, the two versions of the scenarios are identical. Such a minor difference between the two scenarios decreases 
the power of the manipulation and the likelihood of detecting a significant effect; however, given the construct validity concerns, this is necessary to establish causality in interpreting the findings. In summary, each scenario has a source domain and a target domain $\left(\mathrm{D}_{\mathrm{i}}\right.$ and $\left.\mathrm{D}_{\mathrm{j}}\right)$. Once the domain pairs were chosen in a scenario, they automatically determined the magnitude of the similarity construct for that particular opportunity. More than 60 pairings were identified as potential instruments.

The fact that there were no previous data on the instruments' validity made a separate pretest study compulsory. Therefore, I conducted a study with a separate sample of 315 undergraduate business students to capture the participants’ perceptions. Participants read a subset of the scenarios and answered questions corresponding to the two independent variables: need/routine inspiration and cognitive distance. At the end of each session, I held a discussion session with the participants so that they could elaborate on their understanding of the opportunities.

The Need/Routine manipulation had the intended effect about $75 \%$ of the time. In other words, after reading the scenarios, participants identified whether the opportunity was inspired by the need or by the routine correctly $75 \%$ of the time. The amount of time spent reading the scenarios had a significant effect on the probability that the manipulation worked as intended. Since participants received credit only for participating in the experiment (and not for the quality of their participation), not all were motivated to pay attention to the subtle cues in the scenarios. The choice of a subtle treatment reduces the power to detect an effect; however, it substantially improves our confidence in the causal interpretation. The sample scenarios in Appendix A are almost identical word by word. A statistically significant betweensubjects difference can be confidently attributed to the causal effect of the analogical properties because of the intricate design of the experiment that is described in the next section.

Three separate questions captured the participants' similarity evaluations. The first question was asked after they read each scenario. After participants identified the source domain and the target domain, they were asked to state how similar these two domains were to each other. For each $\left(D_{i}, D_{j}\right)$ pair shown to the participant, a similarity rating was collected on a 4-point Likert scale (very dissimilar slightly dissimilar - slightly similar - very similar). The second similarity question appeared after they 
evaluated all scenarios. A manifestation of the cognitive distance construct is the applicability of the source routine in the target domain without significant transformation. When the domains are similar, the routine can be transferred rather easily; but when the domains are distant, the routine might have to transform significantly. In order to capture that insight, I asked participants to pick a manager for the business among five candidates with five different professional backgrounds. They ranked each candidate according to how useful his or her experience would be for the focal business. For each $\left(D_{i}, D_{j}\right)$ pair shown to the participant, a similarity rating was collected as the average rank among the five alternatives. Finally, the third question was asked to elicit a direct similarity evaluation of all possible $\left(D_{i}, D_{j}\right)$ combinations. Participants ranked each business simply in terms of its similarity to the focal business. The average rank was calculated for each combination.

I aggregated the data and determined cut-off points to differentiate among domain pairs. For some scenarios, there was convergence between the three similarity questions. For example, it was apparent that the "jewelry" domain and the "watch" domain created a "similar" condition. In contrast, "movies" and "paintings" domains created a "distant” condition. For some others, answers did not converge. For example, the distance between "tuxedo" and "watch” varied greatly based on how similarity was measured. These domain combinations were not appropriate instruments and thus were excluded from the main study. At the end of this pretest experiment, I chose the three most discriminating scenarios per condition to use in the main study as the treatments. Two other experts, one familiar with the theory and the other unfamiliar with the theory but knowledgeable about the method, verified the coding of the scenarios.

\section{Internal validity}

Recall bias. Using a limited set of domains in several conditions maximizes the internal validity of the findings. To address the potential for recall bias that might arise due to re-using the domains, I incorporate some constraints. First, once I used a domain as a target in a scenario, the participant could not see it again for the rest of the experiment. For instance, after I asked a person for his evaluation of the “online watch rental” business, he could not see the same business as a source domain for another 
condition. Since it had already been portrayed as a hypothetical business, the credibility of the opportunity that uses "online watch rental” as a source would be questionable. Second, I did not use the same business as a target more than once. Even if the source domain was a different one, the participant's evaluation could not be an independent observation, because he already had evaluated the "online watch rental” idea. Third, once I used a domain as a source in a scenario, I did not subsequently use it as a target in a different scenario. I thus implemented a sophisticated delivery system to ensure that none of the above constraints was violated. As a part of this delivery system, the scenarios were presented to participants in a random order so that there was no ordering effect.

Attention bias. Because of the above constraints and the cognitive load on participants, it was impractical to expose a participant to more than three scenarios. That resulted in missing cells in a 3x2 within-subject design. The alternative between-subject design would result in the loss of valuable information. As an economizing solution, I implemented a mixed design with incomplete cells. I treated each independent variable as a within-subject variable, albeit separately. In this economizing solution, the online delivery system made sure that every participant was exposed to every level of the independent variables. In other words, each participant evaluated one similar, one moderate, and one distant scenario, while making sure that at least one of these scenarios was need-inspired and one was routine-inspired.

Instrument reliability. Since this was the first time that these scenarios were used, I could not be fully confident that the findings would be the consequence of the independent variables. It is possible that the choice of a particular domain in a scenario could create the effect. For instance, the opportunity for the “online jewelry” business might get high evaluations simply because people like shiny objects. Therefore, I used multiple scenarios for each condition. Recall that after conducting the pretest experiment that focused on the scenario validation, I identified the most discriminating three scenarios to serve as treatments for each condition. Figure 4 below depicts the implementation details.

Insert Figure 4 about here 
In summary, the experiment had the 3x2 design illustrated in Figure 4. Each group was implemented with the following constraints: (1) Domain Similarity was a within-subject variable (that is, each group had one Similar, one Moderate, and one Distant scenario); (2) Inspiration was a within-subject variable (that is, each group had at least one Need-inspired and one Routine-inspired scenario); and (3) When a business domain was used as a target, it did not recur in any other scenario for that group.

\section{Manipulation checks}

The manipulation check for the Inspiration variable is relatively straightforward. After each scenario, the participants answered three questions that asked in different ways whether the scenario was a need-inspired scenario or a routine-inspired scenario. If the manipulation does not induce the independent variable, it is unreasonable to expect it to have effects on evaluation. Even if there are effects, they will not be due to the predictor variable. All three manipulation check questions had only two possible answers (corresponding to need-inspired or routine-inspired options). Additionally, two attention check questions asked the participant to identify the domains mentioned in the scenarios they read. Inability to recall this information accurately would impair the participant's judgment of the opportunities.

Results below in Table 3 report two levels of manipulation checks. A strict manipulation check that required accurate results for all attention and manipulation check questions removed 174 participants out of the analysis. The participants who did not pass the manipulation check did not differ from those who passed in terms of age, gender, ethnicity, or major. The guidelines of the behavioral lab required that the participants receive the course credit solely for participation and this was made very clear to them during all stages of the experiment. The lack of incentives to pay attention to the subtle stimuli used in this experiment might be a reason for the failure rate (Oppenheimer et al., 2009). Table 3 also reports consistent results when only those who passed the simple attention check are included (85\% of the sample).

Recall that after the pretest, I assigned each scenario to the Similar, Moderate, or Distant condition. As a check of that manipulation, I asked each participant to rate the similarity of all available domain 
pairs in the main study as well. I asked these questions after the participants finished evaluating all the scenarios in order not to confound the dependent variable. Results show that the first level of the Domain Similarity manipulation worked as predicted. Participants did not perceive the distinction between Moderate and Distant conditions, however, even though these two categories collectively were significantly differentiated from Similar scenarios. Therefore, I aggregated the evaluations of the last two conditions into one. After creating a new condition that is simply the average of the last two conditions, the revised design for the purposes of the analysis had only two levels: Similar and Distant.

\section{Dependent and control variables}

Evaluation is the outcome of the initial entrepreneurial judgment under investigation in this study. It corresponds to the end of the first stage in the two-stage entrepreneurial action model developed by McMullen and Shepherd (2006). At this stage, the prospective entrepreneur recognizes that there exists a potentially profitable business opportunity associated with a particular idea, but the person has not yet decided whether to pursue the opportunity. McMullen and Shepherd denote this stage of entrepreneurial action as the third-person opportunity. Accordingly, I measured Evaluation from a third-person perspective, focusing on the opportunity itself. This is in contrast to asking the participant to speculate about starting a business herself or himself. Such priming would invoke individual effects that would confound the results and would not take advantage of the laboratory experiment, which can precisely focus on the intended dependent variation (Schade and Burmeister, 2009).

To measure Evaluation, I used three separate 5-point Likert items. After reading each scenario, the participants answered the following questions: "How attractive do you think the entrepreneurial opportunity described in this scenario is?” [1: Not attractive at all; 5: Very attractive], "How would you predict the success of a company based on this opportunity?” [1: Very unprofitable; 5: Very profitable], and "How likely would you recommend Barbara Johnson to start a business based on this opportunity?" [1: Definitely not recommend; 5: Definitely recommend]. The questions are from a third-person perspective in the sense that the participant is not burdened by having to weigh starting this business herself or himself. 
Dependent variable questions are intended to capture an underlying Evaluation construct. A principal component analysis shows that these three questions indeed capture one underlying variation. The first component captures $85 \%$ of the total variation of the three variables. The component score coefficients of the dependent variables were $0.35,0.36$, and 0.37 . In other words, each variable contributed equally to the component. In addition, the Kaiser-Meyer-Olkin Measure of Sampling Adequacy was 0.746, suggesting that there might be underlying factors. Finally, Bartlett's test of sphericity refuted the null hypothesis very strongly (approx. chi-square: 22,248; df: 3; p-value: 0.000). Therefore, I calculated a single Evaluation score for each opportunity for each participant. The single dependent variable rating is a simple average of the three variables. Running all of the analyses reported below using the factor loadings does not change the results, nor does running all of the analyses reported below for each individual dependent variable question change the results.

The benefit of designing the experiment such that the independent variables are within-subject variables is that it eliminates alternative explanations for the findings. This in turn reduces the import of control variables that are common in survey methods. For the purposes of post-hoc analyses, however, I include the following control variables used in similar studies. I measure prior knowledge of the business domains, the most widely used explanation in the literature to explain entrepreneurial judgment (e.g. Furr et al., 2012; Michael and Combs, 2008; Shane, 2000), using four items adapted from Grégoire (2005:191). I measure prior entrepreneurial activity by the numbers of firms the participants had founded, of start-ups they were involved with as an employee, of entrepreneurship programs completed, and of courses related to entrepreneurship taken. Because Netflix's business model is used as a source domain in many scenarios, the participant's prior experience with it is also measured with dummy variables (awareness of the business, awareness of the website, familiarity with some customers, being a customer). Finally, I also measure the individual's risk-taking propensity using nine items taken from Weber, Blais, and Betz (2002). 


\section{Results}

The average age of the 179 participants who passed the manipulation check in the study is 20.2; $55 \%$ of them are male; and 65\% of them reported Caucasian ethnicity. $72 \%$ of them reported majoring in an area of business. Table 2 presents descriptive statistics of the key variables in this study.

Insert Table 2 about here

\section{Test of hypotheses}

The complexity of the experimental design has dividends in the simplicity of the data analysis. I tested the hypotheses using repeated measures ANOVA. The theoretical model proposes that if opportunities can be represented as analogies in the mind of the individual, then the two analogical properties of the opportunities may matter in terms of how individuals evaluate them. Alternatively, if analogy construction does not matter, then there should be no difference in the evaluation of an opportunity based on a difference in analogy construction. For instance, participants should evaluate the online art rental opportunity described in Appendix A, regardless of its construction, as a need-inspired opportunity or a routine-inspired opportunity. The scenarios are almost identical except for the protagonist's inspiration to construct an analogy. In contrast, if the analogical model matters, Hypothesis 1states that participants will perceive Need-inspired opportunities as less uncertain analogies and hence judge them more positively. In parallel, the cognitive distance between the source and the domain should matter only if the individuals relate to the analogical construction. Otherwise, Barb’s Art Rental is the same opportunity regardless of what domain the original inspiration comes from. Hypothesis 2 proposes that individuals will be sensitive to that cognitive distance and judge similar opportunities more positively than distant ones.

The results show that Similar opportunities are indeed evaluated more positively than Distant ones. In the first subsample with strict manipulation checks, Similar opportunities received a rating of 3.153 out 5, whereas Distant opportunities received a rating of 2.851. ANOVA results show that the difference is 
statistically significant $(F[178]=14.849 ; p=.000)$. A robustness check by comparing only the nonaggregated Distant opportunities show consistent results $(F[178]=13.645 ; p=.000)$. Likewise, in support of Hypothesis 2, participants rated Need-inspired opportunities more positively than Routineinspired opportunities. The Need-inspired opportunities have a mean rating of 3.043, whereas the latter mean is $2.846(F[178]=6.935 ; p=.009)$.

The results are reasonably sensitive to the manipulation checks ${ }^{1}$. Second row of Table 3 reports the results when $85 \%$ of the sample, who answered only the attention checks accurately, is included in the analysis. Both hypotheses are strongly supported in this case as well. When the entire sample is used in the analysis, hypothesis 1 is marginally supported $(p=.069)$ and hypothesis 2 is strongly supported $(p=$ $.005)$.

Insert Table 3 about here

In post-hoc analyses, most control variables did not show any effects on opportunity evaluation. Notably, prior founding experience or prior entrepreneurship education did not have any influence. On the other hand, gender turned out to be the most interesting variable in post-hoc analyses. This study did not theorize any differences in opportunity evaluation based on gender; however, it is significantly correlated with many other variables. Females evaluated almost all types of opportunities, except routine-inspired, more positively than males. A cursory explanation is the difference in attitudes between genders. More interestingly, this difference cannot be based on risk-taking attitudes because females scored significantly below males in terms of their propensity to accept risks. This result is consistent with findings from recent studies on optimism (Hmieleski and Baron, 2009), though the question of why females would be more optimistic than males in opportunity evaluation remains available for future research.

\footnotetext{
${ }^{1}$ The dilution of statistical significance as more of the sample is included in the analysis is revealing. Even though increasing the sample size increases the power of a statistical test, the p-values decrease in this case. When I test the hypotheses on those who answered the manipulation checks inaccurately, neither hypotheses receive support ( $\mathrm{p}$-values $>0.79$ ). Thus, the dilution of the significance can be attributed to whom the manipulation did not induce the desired effect. This fosters my confidence in the causality uncovered by the experiment.
} 


\section{Discussion}

Not all opportunities are the same, and their heterogeneity matters for their judgment. That statement may seem intuitive; but scholarly literature on entrepreneurship has not yet focused on that variation satisfactorily (Grégoire and Shepherd, 2012). Most research to date focuses on the individual traits, the entrepreneurial process, or the outcomes of this process. Opportunity is also a central construct in entrepreneurship (Shane and Venkataraman, 2000), and this study advances the literature by enriching its conceptualization (Short et al., 2010). Recent efforts to focus on the opportunity ideas themselves, as opposed to their outcomes, hint at why it has been difficult to do so (e.g. Dahlqvist and Wiklund, 2012; Samuelsson and Davidsson, 2009; Smith et al., 2009a). We are not even certain where to look for the epistemological underpinnings of an opportunity when it is only an idea, a vision (Alvarez and Barney, 2010).

Philosophical problems notwithstanding, there is a concrete fact that entrepreneurs and their investors must deal with continuously: Novel ideas, such as those behind Google, Netflix, and Amazon, are difficult to judge. In novel circumstances, there are no historical data to form the basis for accurate predictions, and therefore, entrepreneurs encounter uncertainty (Knight, 1921), which leads to hesitancy and doubt, blocking action (McMullen and Shepherd, 2006). As an uncertainty resolution mechanism, entrepreneurs, investors (Cornelissen and Clarke, 2010), and managers (Gary et al., 2012; Gavetti et al., 2005) use analogy in communication, yet this study is the first to explore the formal analogical representation of opportunity ideas from the perspective of the entrepreneur's mind.

The findings on analogy presented in this study identify two ways in which opportunities differ that have not been previously explored: the inspiration behind the idea and the cognitive distance between the domains. The analogical model presented in this study complements existing theories in several ways. First, the analogy model utilizes another instance of cognitive scripts, as the image of the firm routines in the mind of the individual are conceptualized as scripts. This complements previous research, which demonstrates that entrepreneurs invoke and enact cognitive scripts as they act entrepreneurially (Smith et 
al., 2009b). The prospective entrepreneur stores the firm routines in a given domain in the memory and compares them as she makes similarity judgments. Based on the correspondence between these two sets of events, she reaches some conclusions. The ability to construct analogies is shared by all individuals, not only experienced entrepreneurs (Hofstadter, 2001). Further research on entrepreneurial scripts can investigate how individuals use them to construct analogies.

Second, the analogy model contributes another instance of the pattern recognition mechanism, complementing the prototype research, which demonstrates that entrepreneurs compare the set of events to their prototype of an entrepreneurial opportunity (Baron and Ensley, 2006). The prospective entrepreneur is recognizing an opportunity when a routine is transferred over to a new business domain to satisfy a need. The success of prototype matching may depend on the properties of the analogy construction. If the domains are too distant or if the opportunity is motivated by the routine, the individual may be less likely to register a match to the prototype. Further research on opportunity prototypes could investigate the effects of analogical properties on pattern recognition.

Finally, there are significant complementarities between the models of structural alignment and analogy presented in this paper. According to the analogical model in this study, an opportunity is a routine-need combination brought together in a business domain. The finding that the cognitive distance between two domains negatively influences an opportunity’s evaluation helps contextualize the findings of Grégoire and Shepherd's (2012) recent study. These researchers were concerned, for example, that entrepreneurs had trouble overlooking superficial dissimilarities in order to see the structural similarities. The findings in this study can help explain that tendency. Superficial dissimilarities between the domains may have increased the cognitive distance between those domains. Highly innovative opportunities (Samuelsson and Davidsson, 2009) might utilize structural similarities which might also contain superficial dissimilarities (Grégoire and Shepherd, 2012). The evidence presented here regarding the inspiration behind the analogy can help alleviate that valid concern. If the entrepreneurs construct the analogy from a need-based inspiration, they are more likely to evaluate it positively. In these cases, once the entrepreneurs recognize the opportunity, they will be better served by adopting a need-inspired 
communication strategy using metaphors and other linguistic devices based on the needs of the customers in the target domain (Cornelissen and Clarke, 2010).

The experimental design in this study assumed the analogical representation of opportunities and did not test whether opportunities can also be represented in the mind using other cognitive mechanisms. Due to the complexity of the cognitive tasks associated with entrepreneurial behavior, however, all of the knowledge representation models are likely to exist in the mind simultaneously. Furthermore, there may be patterns in the type of opportunities and the cognitive mechanisms. For instance, analogy may capture the nature of some opportunities, e.g. Webvan, better than others, e.g. Microsoft. An intriguing research agenda would be to examine how these cognitive mechanisms can coexist in the mind of the entrepreneur regarding one particular opportunity.

The finding that the evaluation of opportunities depends on their analogical properties provides further evidence supporting a cognitive approach to examine entrepreneurial judgment (Corbett, 2005; Grégoire et al., 2011). However, it does not inform us about the effects of individual characteristics or the outcomes of the ventures based on these analogies. An individual characteristic such as alertness, for example, might be influential in identifying analogies between distant domains (Gaglio and Katz, 2001). Although this study did not focus on differences among individuals, further studies might investigate how individuals differ in their tendencies to construct and believe in analogies. An explanation could be built around optimistic disposition, for example. Prospective entrepreneurs' optimism may allow them to have confidence in analogies that may lead to unsuccessful outcomes (Hmieleski and Baron, 2009). Although the post-hoc analysis in this study did not show any differences based on participants' previous entrepreneurial experience, further theory development is needed on its effect on analogy construction and evaluation of opportunities. Future research could investigate the confluence of individual factors and environmental conditions on analogy construction and success.

\section{Boundary conditions}

The dependent variable in this study is the third-person evaluation of entrepreneurial opportunities. That implies that the opportunity is already formulated by or for the individual. Therefore, the findings of 
this study do not reveal immediate insights about the discovery of opportunities. Furthermore, positive evaluation is a necessary but insufficient condition for behavior. Hence, the interpretation of the findings should take the additional stages between evaluation and action into account. It is safe to assume, however, that action will not occur unless the individual makes a positive evaluation of an opportunity.

An important assumption underpinning both the theory and the empirical instruments in this study is that the opportunity germinates from a single novel idea. Even though there is considerable face validity to this assumption, there may be cases in which the opportunity is a combination of several ideas simultaneously. Findings of this study are bound by those opportunities in which the individual can identify a single analogy as the core idea behind the opportunities. Furthermore, this study did not consider whether the routines needed to transform as they were carried to a target domain in order to satisfy the target need more effectively. The adaptability of the source routine to the target domain could be a predictor of success for the venture that is built on an analogical transformation. An opportunity for further research exists in modeling that transformation as knowledge from one domain is carried over to another domain to create an entrepreneurial opportunity.

Finally, during the testing of the hypotheses, the participants learned about and evaluated opportunities during a relatively short period in the laboratory. Although an experimental setup can resemble entrepreneurial decision making because of its ability to isolate the variables of interest (Schade and Burmeister, 2009), the findings are still based on the initial evaluations. It is conceivable that individuals might modify their evaluations as they think about the opportunities for a longer time or as more information becomes available (Dimov, 2007a; Uygur and Kim, 2013). The corroboration of the hypotheses in this study is particularly relevant to explain the "intuition” or "gut feeling” many entrepreneurs and researchers mention. Further research could investigate how sticky the initial evaluations are for the time spanning the entrepreneurial process and beyond (Michael, 2002).

\section{Practical implications}

A noteworthy practical implication of this study is that understanding the construction of opportunities as analogies can help generate new opportunities. The section on the development of 
hypothetical scenarios can serve as a preliminary template for potential entrepreneurs and senior managers to discover new opportunities. Constructing analogies in order to discover entrepreneurial opportunities in turn has further implications. Being aware of the discovery mechanism of the opportunity, for example, can help entrepreneurs see the shortcomings of their ideas. Awareness might lead entrepreneurs to refine their intuitive judgments and identify weaknesses. For instance, if there is a structural difference between the domains, the transferred knowledge is more likely to fail (Gentner, 1983; Grégoire et al., 2010a). Cognitive processes are highly personal to the individual, and the results of this study support the contention that potential entrepreneurs should understand the underpinning mechanisms.

Analogy is a universal cognitive mechanism shared by all, and thus analogy can help entrepreneurs better communicate their justifications for new business ideas to investors and other stakeholders. Others are more likely to understand the opportunity and relate to the entrepreneur when they can follow the implicit thought process behind the opportunity. Returning to the well-known entrepreneurial stories that opened this text, the analogical properties of these opportunities might have played role in their evaluation. The cognitive distance between the analogs were too distant for the Netflix opportunity: The flat-fee payment routine of the gym did not resemble the payment routine of the video rental stores, nor did mail-order business resemble retail business. Similarly for Amazon, the cognitive distance between bookstores and communication over the internet was simply too large for others to evaluate the opportunity positively. In contrast, Webvan had a very strong analogical story to tell in transferring the online business routines to satisfy grocery needs and was able to gather significant interest in the opportunity.

This study shows that substantial cognitive distances between the domains lead to lower evaluations. Likewise, opportunities that are inspired by routines correlate with lower evaluations. It is uncertain, however, whether these low evaluations are predictors of low future performance. It would be in the best interest of potential investors to understand their own cognitive biases involved in reaching a judgment. 


\section{Conclusion}

Cognitive studies rely on hypothetical scenario experiments because they offer certain advantages, such as significant face validity and the capacity to exert strong causal arguments. Entrepreneurial cognition research, however, has not adopted this methodology extensively (Grégoire et al., 2010b). The methodology used in this study thus can serve as a template demonstrating the validity of using hypothetical scenarios in entrepreneurship research (cf. Grichnik et al., 2010; Loch et al., 2013). This paper identifies several threats to internal validity posed by this method and provides solutions for use in further research. The results of this study can serve as a basis for further empirical cognitive studies in entrepreneurship research by providing a method to connect low-level cognitive phenomena, such as analogical processes, to high-level business concepts, such as entrepreneurial opportunity.

The accessibility of cognitive science methods and theories can help entrepreneurship researchers tackle difficult but central puzzles (Baron, 2004; Grégoire et al., 2011; Krueger, 2003). A central puzzle addressed in this study is the representation of the opportunity in the mind of the prospective entrepreneur (Shaver and Scott, 1991). The organization of prior business knowledge in the mind is a theme that resonates with recent advances in the social science literature. Strategic management research has long inquired about the role of knowledge in firm existence and sustainability (Grant, 1996; Kogut and Zander, 1992; Nelson and Winter, 1982). Particularly in recent years, there is an interest in understanding the cognitive foundations of this knowledge (e.g. Journal of Management Studies December 2012 Special Issue; Bingham and Kahl, 2013; Eggers and Kaplan, 2013). It is not surprising that the knowledge structure question is also a central one for cognitive scientists. In particular, the representation of novel ideas using prior knowledge has been a focus (Gentner et al., 2001; Thagard, 1992). When a novel idea takes the form of an opportunity to generate profits through a firm organization, the representation problem becomes central to entrepreneurship research. We need to address the question of how businesses emerge (Rumelt, 1987), using the perspective of the individual who envisions the business 
(Dimov, 2004). The convergence of strategic management, cognitive science, and entrepreneurship research on the puzzle of opportunity representation promises an answer to this important question. An entrepreneurial opportunity signifies a new means-ends relationship (Busenitz, et al., 2003; Eckhardt and Shane, 2003; Shane, 2004). In this study, I provide a cognitive model of that relationship, which has been lacking despite the wide usage of the term in previous research. Relying on the knowledge-based view of the firm, I conceptualize the relationship as a routine satisfying a customer need. An entrepreneurial opportunity indeed signifies a new means-ends relationship, because it suggests a new routine-need combination that starts as a knowledge proposition in the entrepreneur's mind and can culminate in a firm organization. By demonstrating that analogical properties matter to opportunity evaluation, the empirical results of this study contribute to our understanding of the entrepreneurial judgment puzzle in the mind of the entrepreneur. 


\section{APPENDIX A}

\section{Sample Scenario (Source: Netflix, Target: Art Paintings, Need-Inspired)}

\section{Barb’s Art Rental}

Barbara Johnson lives in New York City. She has recently received a promotion in the company that she had been working for and she makes a comfortable income. As she plans to re-decorate her apartment she realizes that she doesn't find the expensive paintings that hang on the walls very interesting anymore. She paid large sums for each painting. She doesn't think that she can afford to get rid of them and buy new ones from the local fine art store or the museum shop. As she thinks about that problem she stumbles upon a business idea.

What if it was possible to rent expensive art for long periods of time and exchange it when you get bored? The business would be similar to Netflix.com, which offers movies for rent. The customers of Netflix.com pay a flat monthly membership fee. They order the movies online and receive them in the mail. They get to keep the movies as long as they want. Whenever they need to get a new item, they simply mail the movie back to the firm. Then, Netflix.com sends the customer another movie he or she wanted.

Barbara thinks about the potential of a similar business for paintings. The customers would order the paintings from an online website and receive them by special delivery. They would keep them on display at home as long as they wanted at a flat monthly membership fee. When they wanted new paintings they would order them from Barbara's store, which would pick up the old paintings and deliver the new ones. 


\section{Sample Scenario (Source: Netflix, Target: Art Paintings, Routine-Inspired)}

\section{Barb’s Art Rental}

Barbara Johnson has lived in New York for ten years. She has been renting movies from Netflix.com for a year now. The customers of Netflix.com pay a flat monthly membership fee. They order the movies online and receive them in the mail. They get to keep the movies as long as they want. Whenever they need to get a new item, they simply mail the movie back to the firm. Then, Netflix.com sends the customer another movie he or she wanted.

Barbara was impressed with the idea and started thinking about other situations in which she could apply the same model. She remembered the trouble she went through in decorating her new apartment. One problem was the commitment to the expensive fine art to hang on the walls. She visited many local art stores and museum shops before she could decide on which paintings to buy.

What if it was possible to rent expensive art for long periods of time and exchange it when you get bored? The customers would order the paintings from an online website and receive them by special delivery. They would keep them on display at home as long as they wanted at a flat monthly membership fee. When they wanted new paintings they would order them from Barbara's store, which would pick up the old paintings and deliver the new ones.

* I created about sixty hypothetical opportunities to use in the experiment. At the time of the experiment, a business like Barb’s Art Rental did not exist. As of 2014, there is at least one business, TurningArt, which provides the service. Incidentally, Netflix is mentioned as an inspiration in the descriptions of that business. 


\section{REFERENCES}

Abelson R.P., Black J.B. Introduction. In: Galambos J.A., Abelson R.P., Black J.B. editor editors. Knowledge Structures. Hillsdale, NJ: Lawrence Erlbaum Associates; 1986. p. 1-20.

Acs Z., Audretsch D., Desai S., Welpe I. On experiments in entrepreneurship research. Journal of Economic Behavior \& Organization 2010;76:1-2.

Adaman F., Devine P. A reconsideration of the theory of entrepreneurship: A participatory approach. Review of Political Economy 2002;14:329-355.

Alvarez S.A., Barney J.B. Entrepreneurship and Epistemology: The Philosophical Underpinnings of the Study of Entrepreneurial Opportunities. The Academy of Management Annals 2010;4:557-583.

Baron R.A. The cognitive perspective: a valuable tool for answering entrepreneurship's basic "why” questions. Journal of Business Venturing 2004;19:221.

Baron R.A. Opportunity recognition as pattern recognition: How entrepreneurs "connect the dots" to identify new business opportunities. The Academy of Management Perspectives 2006;20:104-119.

Baron R.A., Ensley M.D. Opportunity recognition as the detection of meaningful patterns: Evidence from comparisons of novice and experienced entrepreneurs. Management Science 2006;52:1331-1344.

Baron R.A., Ward T.B. Expanding Entrepreneurial Cognition's Toolbox: Potential Contributions from the Field of Cognitive Science. Entrepreneurship: Theory \& Practice 2004;28:553-573.

Billinger S., Stieglitz N., Schumacher T.R. Search on Rugged Landscapes: An Experimental Study. Organization Science 2014;25:93-108.

Bingham C.B., Kahl S.J. The Process of Schema Emergence: Assimilation, Deconstruction, Unitization and the Plurality of Analogies. Academy of Management Journal 2013;56:14-34.

Busenitz L.W. Research on Entrepreneurial Alertness. Journal of Small Business Management 1996;34:35-44.

Busenitz L.W., West Iii G.P., Shepherd D., Nelson T., Chandler G.N., Zacharakis A. Entrepreneurship Research in Emergence: Past Trends and Future Directions. Journal of Management 2003;29:285-308.

Cook T.D., Campbell D.T., Day A. Quasi-experimentation: Design \& analysis issues for field settings. Houghton Mifflin Boston; 1979.

Corbett A.C. Experiential learning within the process of opportunity identification and exploitation. Entrepreneurship Theory \& Practice 2005;29:473-491.

Cornelissen J.P., Clarke J.S. Imagining and Rationalizing Opportunities: Inductive Reasoning and the Creation and Justification of New Ventures. The Academy of Management Review 2010;35:539-557.

Csikszentmihalyi M. Creativity : flow and the psychology of discovery and invention. New York: Harper Collins Publishers; 1996. 
Dahlqvist J., Wiklund J. Measuring the market newness of new ventures. Journal of Business Venturing 2012;27:185-196.

Dimov D. Beyond the single-person, single-insight attribution in understanding entrepreneurial opportunities. Entrepreneurship Theory and Practice 2007a;31:713-731.

Dimov D. From Opportunity Insight to Opportunity Intention: The Importance of Person-Situation Learning Match. Entrepreneurship Theory and Practice 2007b;31:561-583.

Dimov D.P. The Individuality of Opportunity Recognition: A Critical Review and Extension. In: Butler J.E. editor editors. Opportunity Identification and Entrepreneurial Behavior. Greenwich, Conn.: Information Age Publishing; 2004.

Dyer J.H., Gregersen H.B., Christensen C. Entrepreneur Behaviors, Opportunity Recognition, and the Origins of Innovative Ventures. Strategic Entrepreneurship Journal 2008;2:317-338.

Eckhardt J.T., Shane S.A. Opportunities and entrepreneurship. Journal of Management 2003;29:333-349.

Eggers J.P., Kaplan S. Cognition and Capabilities. The Academy of Management Annals 2013;7:293338.

Foss N.J., Klein P.G. Organizing entrepreneurial judgment: a new approach to the firm. Cambridge, UK: Cambridge University Press; 2012.

Furr N.R., Cavarretta F., Garg S. Who Changes Course? The Role of Domain Knowledge and Novel Framing in Making Technology Changes. Strategic Entrepreneurship Journal 2012;6:236-256.

Gaglio C.M., Katz J.A. The psychological basis of opportunity identification: Entrepreneurial alertness. Small Business Economics 2001;16:95-111.

Gary M.S., Wood R.E., Pillinger T. Enhancing mental models, analogical transfer, and performance in strategic decision making. Strategic Management Journal 2012;33:1229-1246.

Gavetti G., Levinthal D.A., Rivkin J.W. Strategy making in novel and complex worlds: the power of analogy. Strategic Management Journal 2005;26:691-712.

Gentner D. Structure-mapping: A theoretical framework for analogy. Cognitive Science 1983;7:155-170.

Gentner D., Holyoak K.J., Kokinov B.N. The analogical mind : perspectives from cognitive science. Cambridge, MA: MIT Press; 2001.

Grant R.M. Toward a knowledge-based theory of the firm. Strategic Management Journal 1996;17:109122.

Grégoire D. Opportunity acknowledgement as a cognitive process of pattern recognition and structural alignment. United States -- Colorado: University of Colorado at Boulder; 2005.

Grégoire D.A., Barr P.S., Shepherd D.A. Cognitive processes of opportunity recognition: The role of structural alignment. Organization Science 2010a;21:413-431.

Grégoire D.A., Corbett A.C., McMullen J.S. The cognitive perspective in entrepreneurship: An agenda for future research. Journal of Management Studies 2011;48:1443-1477. 
Grégoire D.A., Shepherd D.A. Technology-market combinations and the identification of entrepreneurial opportunities: An investigation of the opportunity-individual nexus. Academy of Management Journal 2012;55:753-785.

Grégoire D.A., Shepherd D.A., Schurer Lambert L. Measuring Opportunity-Recognition Beliefs. Organizational Research Methods 2010b;13:114.

Grichnik D., Smeja A., Welpe I. The importance of being emotional: How do emotions affect entrepreneurial opportunity evaluation and exploitation? Journal of Economic Behavior \& Organization 2010;76:15-29.

Gruber M., MacMillan I.C., Thompson J.D. Escaping the Prior Knowledge Corridor: What Shapes the Number and Variety of Market Opportunities Identified Before Market Entry of Technology Start-ups? Organization Science 2013;24:280-300.

Harper D.A. Entrepreneurship and the market process: an enquiry into the growth of knowledge. London, UK: Routledge; 1996.

Haynie J.M., Shepherd D.A., McMullen J.S. An Opportunity for Me? The Role of Resources in Opportunity Evaluation Decisions. Journal of Management Studies 2009;46:337-361.

Hill S.A., Birkinshaw J.M. Idea Sets: Conceptualizing and Measuring a New Unit of Analysis in Entrepreneurship Research. Organizational Research Methods 2010;13:85-113.

Hmieleski K.M., Baron R.A. Entrepreneurs' optimism and new venture performance: A social cognitive perspective. Academy of Management Journal 2009;52:473-488.

Hofstadter D.R. Analogy as the core of cognition. In: Gentner D. editor editors. The analogical mind: Perspectives from cognitive science. 2001. p. 499-538.

Hogarth R.M., Karelaia N. Entrepreneurial Success and Failure: Confidence and Fallible Judgment. Organization Science 2012;23:1733-1747.

Holyoak K.J., Thagard P. Mental leaps : analogy in creative thought. Cambridge, MA: MIT Press; 1995.

Kaul A. Entrepreneurial Action, Unique Assets, and Appropriation Risk: Firms as a Means of Appropriating Profit from Capability Creation. Organization Science 2013.

Kesting P. Why Innovations Have to Overcome Routine. History of Economic Ideas 2007;15:137-156.

Kirzner I.M. Entrepreneurial Discovery and the Competitive Market Process: An Austrian Approach. Journal of Economic Literature 1997;35:60-85.

Knight F.H. Risk, uncertainty and profit. Harper Torchbooks The Academy library, TB 1215P. New York, NY: Harper \& Row, 1965; 1921. p. lxiv, 381-lxiv, 381.

Kogut B., Zander U. Knowledge of the Firm, Combinative Capabilities, and the Replication of Technology. Organization Science: A Journal of the Institute of Management Sciences 1992;3:383-397.

Krueger Jr N.F., Reilly M.D. Competing Models of Entrepreneurial Intentions. Journal of Business Venturing 2000;15:411-432. 
Krueger N.F., Jr. The Cognitive Psychology of Entrepreneurship. In: Audretsch D.B. editor editors. Handbook of entrepreneurial research: An interdisciplinary survey and introduction. Boston; Dordrecht and London: Kluwer Academic; 2003.

Langlois R.N. Subjective Probability and Subjective Economics. New York, NY: C. V. Starr Center for Applied Economics; 1982.

Loch C.H., Sengupta K., Ahmad M.G. The Microevolution of Routines: How Problem Solving and Social Preferences Interact. Organization Science 2013;24:99-115.

Mahoney J.T., Michael S.C. A subjectivist theory of entrepreneurship. In: Alvarez S.A., Agarwal R., Sorenson O. editor editors. Handbook of Entrepreneurship Research: Interdisciplinary Perspectives. New York, NY: Springer; 2005. p. 33-55.

McMullen J.S., Shepherd D.A. Entrepreneurial action and the role of uncertainty in the theory of the entrepreneur. Academy of Management Review 2006;31:132-152.

Michael S.C. Time To Discovery: The Role of Time in the Entrepreneurial Discovery Process. Business Ethics Quarterly 2002;Ruffin Series 3:157-161.

Michael S.C. Transaction cost entrepreneurship. Journal of Business Venturing 2007;22:412-426.

Michael S.C., Combs A.G. Entrepreneurial failure: The case of franchisees. Journal of Small Business Management 2008;46:73-90.

Mitchell R.K., Busenitz L., Lant T., McDougall P.P., Morse E.A., Smith J.B. The Distinctive and Inclusive Domain of Entrepreneurial Cognition Research. Entrepreneurship Theory \& Practice 2004;28:505-518.

Mitchell R.K., Busenitz L.W., Bird B., Gaglio C.M., McMullen J.S., Morse E.A. et al. The central question in entrepreneurial cognition research 2007. Entrepreneurship Theory and Practice 2007;31:1-27.

Mitchell R.K., Smith B., Seawright K.W., Morse E.A. Cross-cultural cognitions and the venture creation decision. Academy of Management Journal 2000;43:974-993.

Mitchell R.K., Smith J.B., Morse E.A., Seawright K.W., Peredo A.M., McKenzie B. Are entrepreneurial cognitions universal? Assessing entrepreneurial cognitions across cultures. Entrepreneurship Theory \& Practice 2002;26:9-32.

Negro G., Leung M.D. “Actual” and Perceptual Effects of Category Spanning. Organization Science 2012;24:684-696.

Nelson R.R., Winter S.G. An evolutionary theory of economic change. Cambridge, MA: Belknap Press of Harvard University Press; 1982.

Oppenheimer D.M., Meyvis T., Davidenko N. Instructional manipulation checks: Detecting satisficing to increase statistical power. Journal of experimental social psychology 2009;45:867-872.

Patel P.C., Fiet J.O. Enhancing the internal validity of entrepreneurship experiments by assessing treatment effects at multiple levels across multiple trials. Journal of Economic Behavior \& Organization 2010;76:127-140. 
Robertson D.C., Anderson E. Control System and Task Environment Effects on Ethical Judgment: An Exploratory Study of Industrial Salespeople. Organization Science 1993;4:617-644.

Rosenkopf L., McGrath P. Advancing the Conceptualization and Operationalization of Novelty in Organizational Research. Organization Science 2011;22:1297-1311.

Rumelt R. Theory, Strategy, and Entrepreneurship. In: Teece D.J. editor editors. The Competitive Challenge: Strategies for Industrial Innovation and Renewal. Cambridge, Mass.: Ballinger; 1987. p. 137158.

Samuelsson M., Davidsson P. Does venture opportunity variation matter? Investigating systematic process differences between innovative and imitative new ventures. Small Business Economics 2009;33:229-255.

Sarasvathy D.K., Simon H.A., Lave L. Perceiving and managing business risks: differences between entrepreneurs and bankers. Journal of Economic Behavior \& Organization 1998;33:207-225.

Sarasvathy S.D. Causation and effectuation: toward a theoretical shift from economic inevitability to entrepreneurial contingency. The Academy of Management Review 2001;26:243-263.

Sarasvathy S.D., Dew N. New market creation through transformation. Journal of Evolutionary Economics 2005;15:533-565.

Schade C., Burmeister K. Experiments on Entrepreneurial Decision Making. Now Publishers Inc; 2009.

Schumpeter J.A. The theory of economic development: An inquiry into profits, capital, credit, interest, and the business cycle. Cambridge, MA: Harvard University Press; 1934.

Shane S. Prior knowledge and the discovery of entrepreneurial opportunities. Organization Science 2000;11:448-469.

Shane S., Venkataraman S. The promise of entrepreneurship as a field of research. Academy of Management Review 2000;25:217-226.

Sharkey N.E. A Model of Knowledge-Based Expectations in Text Comprehension. In: Galambos J.A., Abelson R.P., Black J.B. editor editors. Knowledge Structures. Hillsdale, NJ: Lawrence Erlbaum Associates; 1986. p. 49-70.

Shaver K.G., Scott L.R. Person, Process, Choice: The Psychology of New Venture Creation. Entrepreneurship: Theory \& Practice 1991;16:23-45.

Shook C.L., Priem R.L., McGee J.E. Venture Creation and the Enterprising Individual: A Review and Synthesis. Journal of Management 2003;29:379-399.

Short J.C., Ketchen D.J., Shook C.L., Ireland R.D. The concept of “opportunity” in entrepreneurship research: Past accomplishments and future challenges. Journal of Management 2010;36:40.

Simon M., Shrader R.C. Entrepreneurial actions and optimistic overconfidence: The role of motivated reasoning in new product introductions. Journal of Business Venturing 2012;27:291-309. 
Smith B.R., Matthews C.H., Schenkel M.T. Differences in Entrepreneurial Opportunities: The Role of Tacitness and Codification in Opportunity Identification. Journal of Small Business Management 2009a;47:38-57.

Smith J.B., Mitchell J.R., Mitchell R.K. Entrepreneurial Scripts and the New Transaction Commitment Mindset: Extending the Expert Information Processing Theory Approach to Entrepreneurial Cognition Research. Entrepreneurship: Theory \& Practice 2009b;33:815-844.

Thagard P. Conceptual revolutions. Princeton, N.J.: Princeton University Press; 1992.

Uygur U., Kim S.M. Epiphany and Evolution: How Does Entrepreneurial Judgment Change with Time? Frontiers of Entrepreneurship Research 2013;33:22.

Ward T.B. Cognition, creativity, and entrepreneurship. Journal of Business Venturing 2004;19:173-188.

Weber E.U., Blais A.-R., Betz N.E. A domain-specific risk-attitude scale: measuring risk perceptions and risk behaviors. Journal of Behavioral Decision Making 2002;15:263-290. 
TABLE 1. Threats to Causal Inference

\begin{tabular}{|l|l|l|}
\hline Threat to causality & Explanation & Solution \\
\hline Construct validity & $\begin{array}{l}\text { The scenarios might not represent the } \\
\text { domain similarity levels as intended }\end{array}$ & $\begin{array}{l}\text { Conducted a pretest experiment to } \\
\text { determine the similarity level of } \\
\text { each scenario }\end{array}$ \\
\hline Recall bias & $\begin{array}{l}\text { In a within-subject design, participants } \\
\text { encounter a particular domain more than } \\
\text { once }\end{array}$ & $\begin{array}{l}\text { Implemented detailed constraints on } \\
\text { domain re-use }\end{array}$ \\
\hline Limited attention bias & $\begin{array}{l}\text { Overuse of time and attention resources } \\
\text { might bias the results }\end{array}$ & $\begin{array}{l}\text { Implemented a mixed-design with } \\
\text { incomplete cells to economize }\end{array}$ \\
\hline Grouping effects & $\begin{array}{l}\text { Incomplete cells might lead to grouping } \\
\text { effects if the assignment of treatments co- } \\
\text { varies }\end{array}$ & Counter-balanced the groups \\
\hline Instrument reliability & The scenarios have not been used before & $\begin{array}{l}\text { Used multiple scenarios that passed } \\
\text { the validity test for each condition }\end{array}$ \\
\hline
\end{tabular}

TABLE 2. Descriptive Statistics and Correlations

\begin{tabular}{|l|c|c|l|l|l|l|l|l|l|l|}
\hline Variables & Mean & $\begin{array}{l}\text { Std } \\
\text { dev. }\end{array}$ & 1 & 2 & 3 & 4 & 5 & 6 & 7 & 8 \\
\hline $\begin{array}{l}\text { 1. Evaluation of } \\
\text { Need-inspired Opp. }\end{array}$ & 3.05 & .77 & & & & & & & & \\
\hline $\begin{array}{l}\text { 2. Evaluation of } \\
\text { Routine-inspired Opp. }\end{array}$ & 2.85 & .87 & $.20^{* *}$ & & & & & & & \\
\hline $\begin{array}{l}\text { 3. Evaluation of } \\
\text { Similar Opp. }\end{array}$ & 3.15 & .93 & $.48^{* *}$ & $.53^{* *}$ & & & & & & \\
\hline $\begin{array}{l}\text { 4. Evaluation of } \\
\text { Distant Opp. }\end{array}$ & 2.85 & .67 & $.70^{* *}$ & $.55^{* *}$ & $.17^{*}$ & & & & & \\
\hline 5. Gender ${ }^{\text {a }}$ & 1.45 & .50 & $.21^{* *}$ & .12 & $.15^{*}$ & $.16^{*}$ & & & & \\
\hline 6. Founder ${ }^{b}$ & .07 & .32 & -.08 & -.04 & -.11 & -.02 & -.07 & & & \\
\hline 7. Ent. Workshops ${ }^{c}$ & .30 & .98 & -.14 & .03 & -.00 & -.14 & $-.20^{*}$ & .07 & & \\
\hline 8. Prior Netflix Exp. & 1.49 & .64 & -.01 & -.11 & -.07 & -.07 & -.03 & -.07 & .05 & \\
\hline 9. Risk-taking & -.03 & 1.00 & $.16^{*}$ & -.03 & .06 & .13 & $-.21^{* *}$ & .06 & .09 & .06 \\
\hline
\end{tabular}

${ }^{*}(\mathrm{p}<0.05) ;{ }^{* *}(\mathrm{p}<0.01) ;$ sample size $=179 ;{ }^{\text {a }}$ [1: male; 2 : female]; ${ }^{\mathrm{b}}$ [1: incorporated a business; 0 : not $] ;{ }^{\mathrm{c}}[$ 1: attended entrepreneurship-related workshop or similar program; 0 : not]

TABLE 3. ANOVA Results

\begin{tabular}{|c|c|c|c|c|c|c|c|c|}
\hline $\begin{array}{c}\text { Attention } \\
\text { Check }\end{array}$ & $\begin{array}{c}\text { Manipulation } \\
\text { Check }\end{array}$ & & \multicolumn{3}{|c|}{$\begin{array}{c}\text { H1 } \\
\text { (Need - Routine) }\end{array}$} & \multicolumn{3}{c|}{$\begin{array}{c}\text { H2 } \\
\text { (Similar - Distant) }\end{array}$} \\
\hline $\begin{array}{l}\text { Identified } \\
\text { Domains }\end{array}$ & $\begin{array}{c}\text { Identified } \\
\text { Inspiration }\end{array}$ & $\mathrm{n}$ & $\begin{array}{c}\text { Mean } \\
\text { Diff }\end{array}$ & F-stat & $\begin{array}{c}\text { p- } \\
\text { value }\end{array}$ & $\begin{array}{c}\text { Mean } \\
\text { Diff }\end{array}$ & F-stat & $\begin{array}{c}\mathrm{p}- \\
\text { value }\end{array}$ \\
\hline Accurate & Accurate & 179 & .196 & 6.935 & .009 & .302 & 14.849 & .000 \\
\hline Accurate & All & 306 & .131 & 4.540 & .034 & .190 & 8.599 & .004 \\
\hline
\end{tabular}


FIGURE 1. How to Create a Need-Inspired Entrepreneurial Opportunity through Analogy

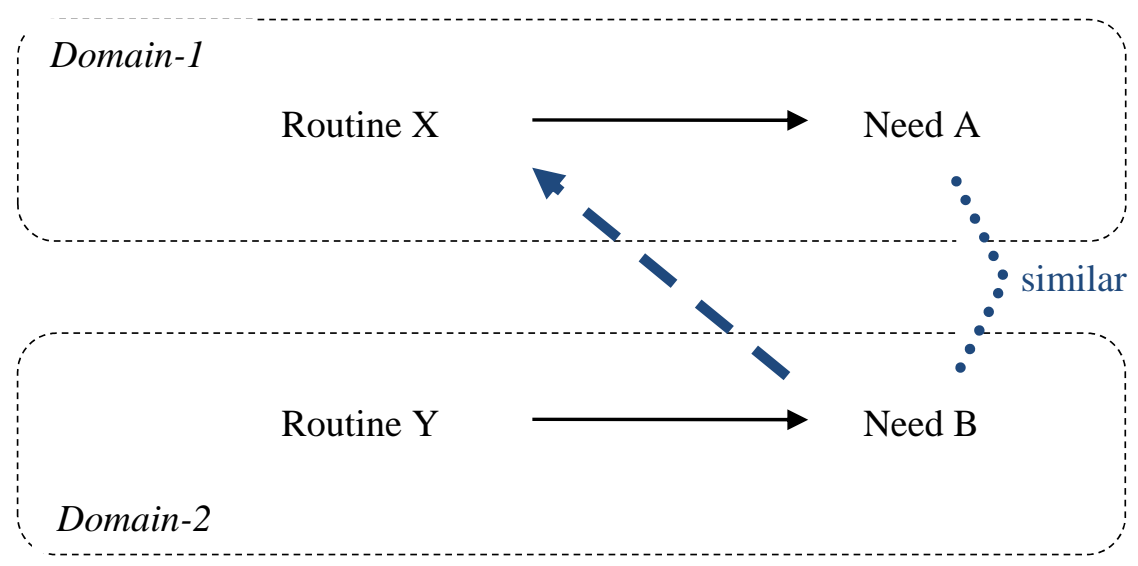

FIGURE 2. How to Create a Routine-Inspired Entrepreneurial Opportunity through Analogy

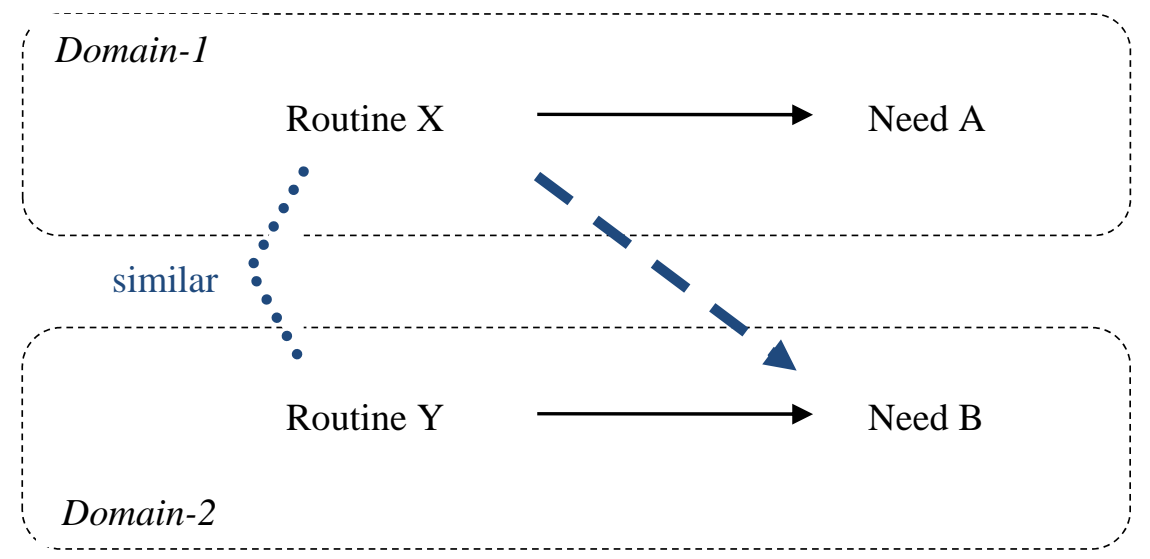


FIGURE 3. Cognitive Distance between Two Domains of an Entrepreneurial Opportunity

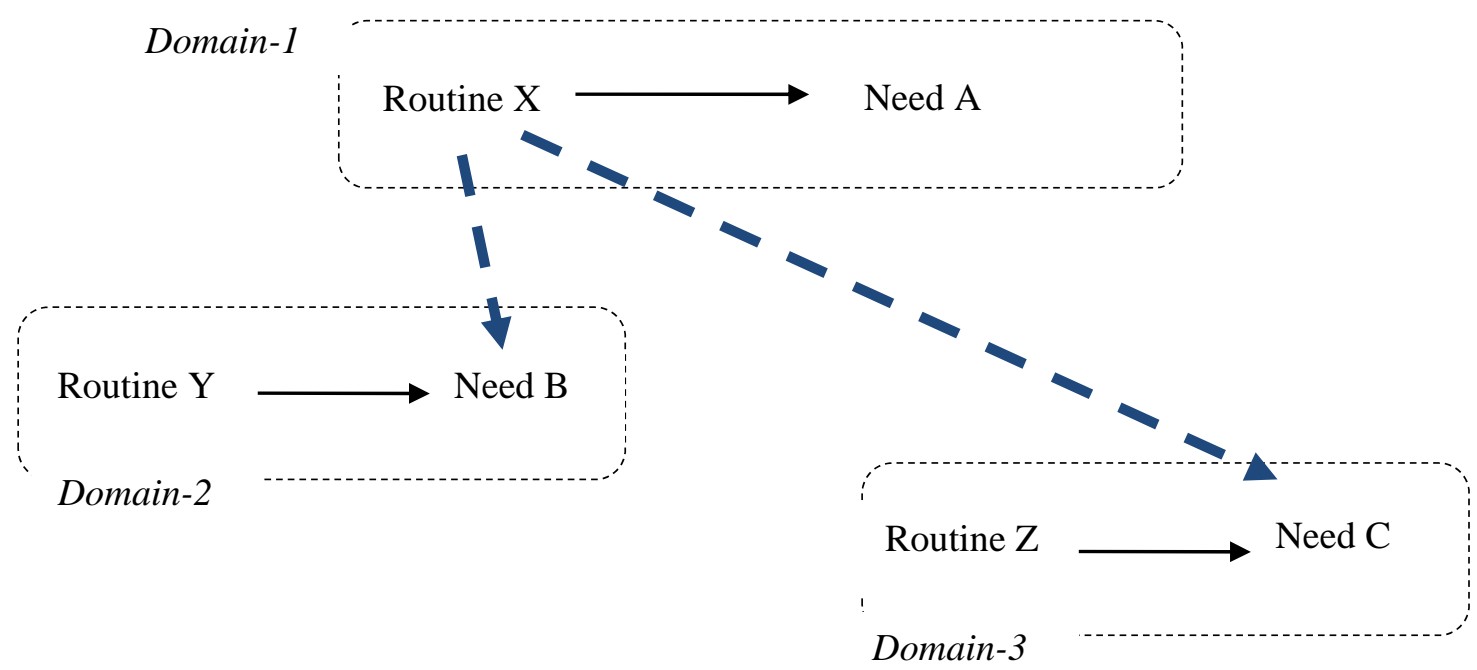




\section{FIGURE 4. Experimental Design with Treatment Groups}

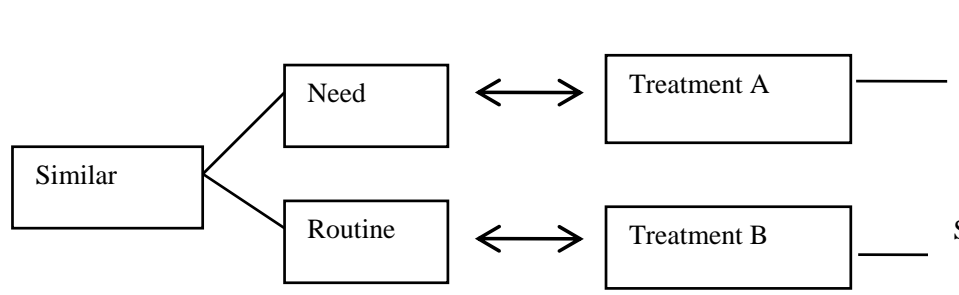

Scenario A1

Scenario A2

Scenario A3

Scenario B1

Scenario B2

Scenario B3
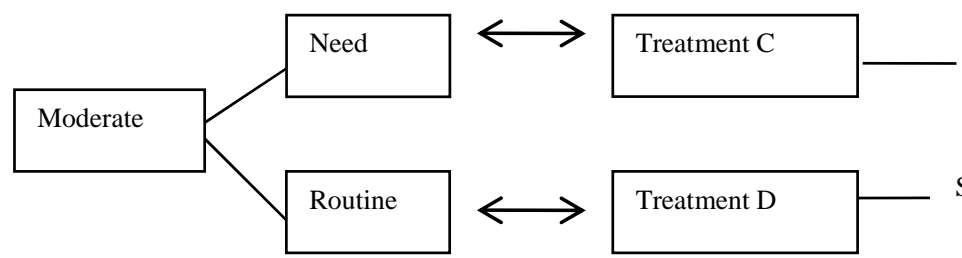

Scenario C1

Scenario C2

Scenario C3

Scenario D1

Scenario D2

Scenario D3

Scenario E1

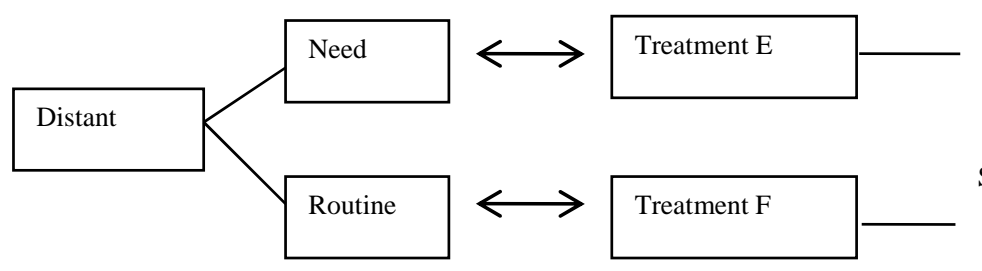

Scenario E2

Scenario E3

Scenario F1

Scenario F2

Scenario F3

$\begin{array}{llll}\text { FACTOR } 1 & \text { FACTOR } 2 & \text { CONDITIONS }\end{array}$ 